\section{Characterisation of copper alloy antique ornamental accessories found in Northern Albania}

\author{
Olta Çakaj, ${ }^{1}$ Edlira Duka, ${ }^{2}$ Zamir Tafilica, ${ }^{3}$ \\ Frederik Stamati, ${ }^{4}$ Nikolla Civici, ${ }^{5}$ \\ Teuta Dilo' \\ 'Department of Physics, University of \\ Tirana; ${ }^{2}$ Department of Physical \\ Engineering, Polytechnic University of \\ Tirana; ${ }^{3}$ Department of Archeology, \\ Historical Museum of Shkodra; ${ }^{4}$ Centre of \\ Albanological Studies, Tirana; ${ }^{5}$ Centre of \\ Applied Nuclear Physics, University of \\ Tirana, Albania
}

\begin{abstract}
This study was performed to determine the chemical elements used to produce ancient metallic alloys and to understand the manufacture technique of three archaeological founds. It also presents an evaluation method of the objects' authenticity based on the observation of the corrosion products. This article also includes three ornamental accessories $c a$. VIIIV century BC found in the vicinity of Shkodra (Albania). A necklace, a belt application and a button are examined using $X$ ray fluorescence (XRF) to determine the chemical composition and optical microscopy $(\mathrm{OM})$ with reflected and polarised light in order to study the microstructure and the corrosion products. From the XRF results all the objects are bronze, copper-tin and copper-tin-lead alloys. After the OM analysis they are authentic objects (not fake replicas) and might have been produced after a casting process in moulds.
\end{abstract}

\section{Introduction}

The corrosion products study of archaeological objects has authenticity and preservation importance. On the other hand, their chemical composition and production technique examination gives significant information about the cultural and trade developments. Albania lies in Southeast Europe and the mountain areas in its north and southwest territories are rich in minerals particularly in copper, which allowed metallurgy development at an early date. The Iron Age began in the XII century until the $\mathrm{V}$ century BC. The period from the $\mathrm{V}$ to the II century $\mathrm{BC}$ is known as the Period of Illyrian Cities (Ceka, 2000). During Iron Age, bronze was used mainly for ornaments and cult objects production because of its lower hardness leading to higher pliable - compared to iron and also likable colour (Boardman $e t$ al., 1982; Jacques, 1995). Shkodra (Figure 1) was established as a city during the IV century $\mathrm{BC}$ on the hills around the Shkodra castle, near the lake with the city's name on the Northeast of Albania. Its territories were occupied long before the IV century BC and the main activities of the population were farming, agriculture and handicraft production. The few number of weapons found in graves evidences that the population of the area was pacific and not involved in major wars. During the Iron Age, trade connections with Aegean people were not interrupted as many ornamental accessories were imported due to the women fashion interest of the time. The Aegean influence was present even in the ceramics and metals local production (Prendi, 1977-1978; Ceka, 2000).

\section{Materials and Methods}

The objects, samples and their dating were provided from the archaeologist Dr. Tafilica, currently former director of the Historical Museum of Shkodra. In this study: the necklace, the belt application and the button were found in the vicinity areas of Shkodra city and belong to the Illyrian culture (Prendi, 1958). The necklace (VII-VI century BC) is composed of 9 beads ( $0.126 \mathrm{~kg}$ total mass): the first one has a distinguished conical shape and $0.036 \mathrm{~m}$ in length, while the other 8 are smaller $(0.03 \mathrm{~m}$ in length) and consists of two conical parts connected at their bases with four radial thin strings. This necklace is a common ornamental accessory in Northern Illyria (today Mat valley) but almost unknown for the other territories (Prendi, 2008). The belt application (VIIVI century BC) has a mass of $0.2293 \mathrm{~kg}$ and is composed of 24 long elements connected with one other in two points. The length of these elements is $0.076 \mathrm{~m}$, while the thickness is $0.003 \mathrm{~m}$. Each element has 15 little bumps, with two prickle ends. Similar but at the same time distinguishable belt applications are known from the Rakitno and Glasinac cultures (Bosnia and Herzegovina) (Prendi, 2008). The button (VI-IV century BC) is a characteristic element of the Illyrian handicraft culture (precisely Mat culture) (Prendi, 2008). It consists of a half spherical body ( $0.033 \mathrm{~m}$ in diameter) with fissure stripes arising from the top ( 0.017 $m$ total length). The surface of all objects is covered by corrosion and the metal is not visible. In Figure 2 photos of the objects described above and their sketches are shown (Prendi, 2008). For preservation reasons the objects were covered with a varnish layer, hence certain spots on them were polished using abra-
Correspondence: Olta Çakaj, Department of Physics, University of Tirana, boulevard Zogu I, 1001 Tirana, Albania.

Tel./Fax: +355.42.27914.22114.

E-mail: olta.cakaj@fshn.edu.al; oltacakaj@ gmail.com

Key words: copper alloy, X-ray fluorescence, optical microscopy, production technology.

Contributions: OC, data collecting, analysing and interpreting, manuscript writing; ED, supporting with data interpreting; ZT, samples providing, literature supporting and objects dating; FS, manuscript reviewing; NC, X-ray fluorescence analysis supporting; TD, optical microscopy analysis supporting.

Conflict of interests: the authors declare no potential conflict of interests.

Acknowledgments: the authors would like to thank the Department of Archeology, Historical Museum of Shkodra for providing the samples for this study, the Centre of Applied Nuclear Physics and the Faculty of Natural Sciences, University of Tirana for making the analytical equipment available.

This work is licensed under a Creative Commons Attribution 3.0 License (by-nc 3.0).

Received for publication: 8 January 2014.

Revision received: 30 June 2014

Accepted for publication: 10 July 2014.

CC Copyright O. Çakaj et al., 2014

Licensee PAGEPress, Italy

Open Journal of Archaeometry 2014; 2:5506

doi:10.4081/arc.2014.5506

sive paper and solvent in order to remove the varnish. After this process a portable micro $\mathrm{X}$ ray fluorescence (XRF) device Bruker (Daltonics, Fremont, CA, USA) was used to perform the chemical elements qualitative and quantitative analysis. The dimension of the beam spot used in this study is $60 \mathrm{~m}$, detective elements range $\mathrm{Na}(Z=11)-\mathrm{U}(Z=92)$ and the device was associated along with Spectra ARTAX Version 7.2.5.0. and M-Quant-Calib (Bruker) softwares (Potts and West, 2008).

From each object a small sample was removed (volume around $8 \times 10^{-9} \mathrm{~m}^{3}$; Figure 2) in order to obtain maximum metallographic information representative of the whole object. The samples were removed from parts of the objects not visible to the eye while exposed in the museum and the sampling did not damage the structure and shape of these ornaments. The samples were mounted in resin, polished first with silicon carbide papers 500, 1000 , 4000 (corresponding grain diameter 30,18 and $5 \mathrm{~m}$ ), with water as lubricant, and second with cloth, diamante paste $3 \mathrm{~m}$ and DP-Lubricant Blue (MIT, 2003). At first, the micro hardness 
of the mounted samples was measured using Vickers micro hardness test (load used 0.245 $\mathrm{N})$. During the Vickers micro hardness test a $136^{\circ}$ four sided diamond indenter was pressed against the sample's surface and the diagonals of the rhombic trace were measured. This is one of the two tests that are suitable to measure the micro hardness of archaeological metals. The other one is the Brinell micro hardness test. The Vickers micro hardness test was used to support the results of the objects' chemical composition and their production technique. Pure metallic elements have lower micro hardness values (HV) than metallic alloys. These values also vary with the application of different mechanical processes performed on the alloy. Second, the samples' corrosion products were observed using optical microscopy with polarised light. Lastly, after being etched with aqueous ferric chloride ( $0.12 \mathrm{~L}$ distilled water $\mathrm{H}_{2} 0,0.03 \mathrm{~L}$ hydrochloric acid $\mathrm{HCl}, 0.01 \mathrm{~kg}$ ferric chloride $\mathrm{FeCl}_{3}$, best etching interval time $2-8 \mathrm{sec}$ ), the microstructure of the samples' surface was investigated using optical microscopy with reflected light. In this study, Metalloplan Leitz microscope with Vickers indenter (Leica $\mathrm{GmbH}$, Wetzlar, Germany) was used to measure the samples' micro hardness, while Kozo XJP300 microscope (Kozo Optics, Nanjing, China) was used along with Sony TCC-8.1 camera (Sony, Tokyo, Japan) and TS View Version 1.0.0.1 software to acquire the corrosion and microstructure pictures (Scott, 1991; Wayne, 2009).

\section{Results and Discussion}

Figure 3 shows the XRF spectra of the first spot examined for each object, while the XRF results for each spot along with the corresponding standard deviation are shown in Table 1. The XRF analysis was used to determine the

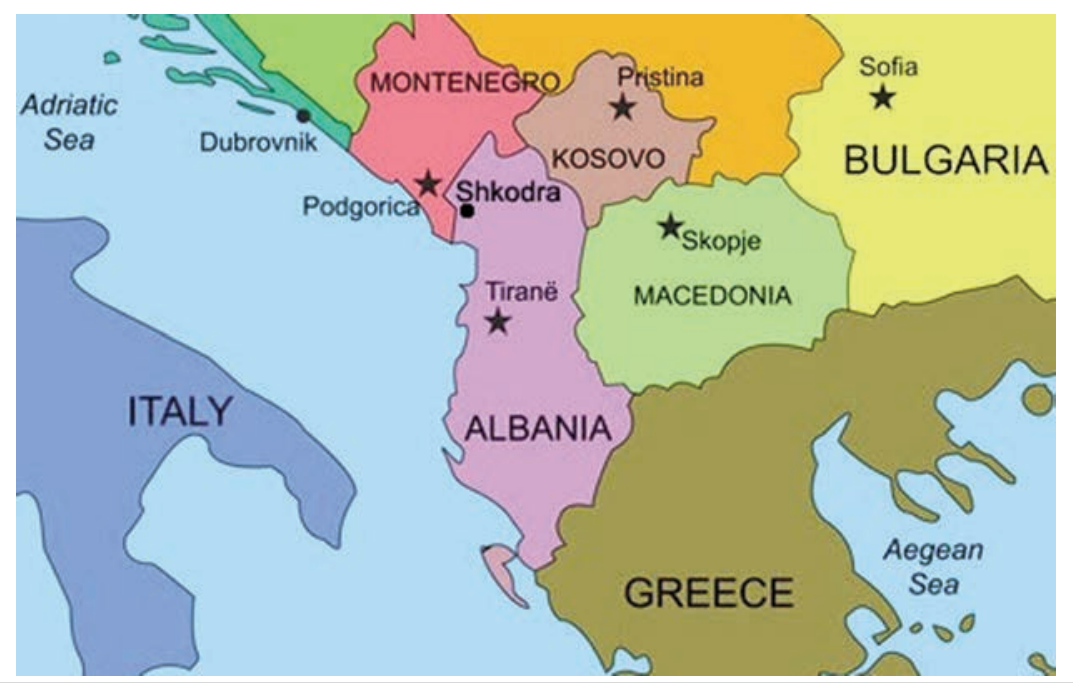

Figure 1. Map of Albania in the Balkans and Shkodra's location in the Northeast of Albania.
A

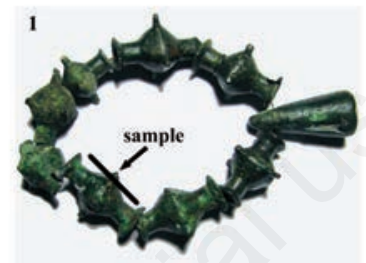

910 if 12 is is is is 17 is is 20

B

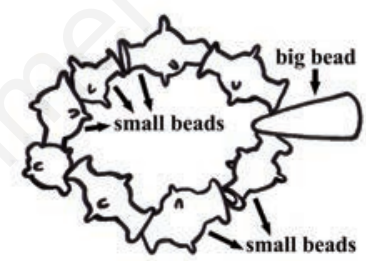

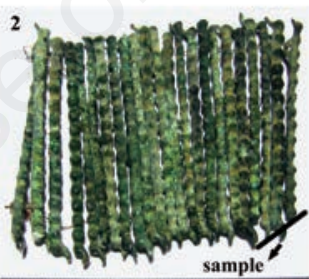
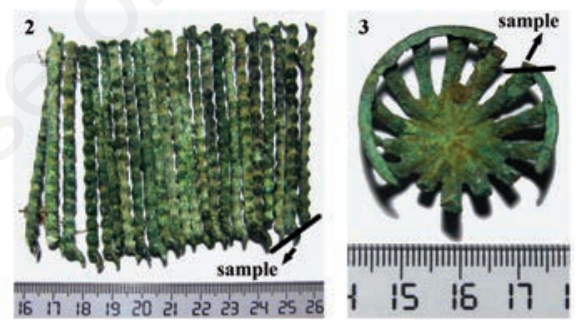
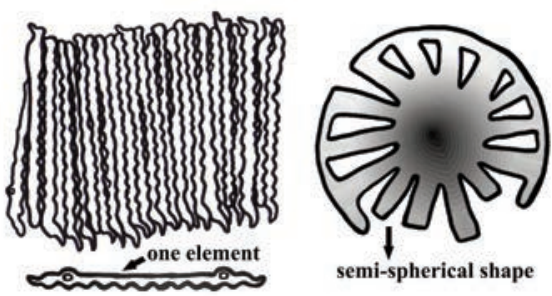

Figure 2. A) The necklace (1), the belt application (2) and the button (3), showing also the position where each sample was taken; B) the corresponding sketches.

Table 1. Elements percentage and standard deviation for the necklace, belt application and the button after $\mathrm{X}$ ray fluorescence analysis.

\begin{tabular}{|c|c|c|c|c|c|c|c|}
\hline \multirow[t]{2}{*}{ Element } & \multicolumn{7}{|c|}{ Object (examined spot) } \\
\hline & $\begin{array}{l}\text { Necklace } \\
\text { VII-VI BC } \\
\text { (big bead, } \\
\text { metal spot) }\end{array}$ & $\begin{array}{l}\text { Necklace } \\
\text { VII-VI BC } \\
\text { (small bead, } \\
\text { metal spot) }\end{array}$ & $\begin{array}{l}\text { Belt application } \\
\text { VII-VI BC } \\
\text { (metal } \\
\text { spot 1) }\end{array}$ & $\begin{array}{l}\text { Belt application } \\
\text { VII-VI BC } \\
\text { (metal } \\
\text { spot 2) }\end{array}$ & $\begin{array}{l}\text { Belt application } \\
\text { VII-VI BC } \\
\text { (corrosion } \\
\text { spot) }\end{array}$ & $\begin{array}{l}\text { Button } \\
\text { VI-IV BC } \\
\text { (top metal } \\
\text { spot) }\end{array}$ & $\begin{array}{c}\text { Button } \\
\text { VI-IV BC } \\
\text { (edge metal } \\
\text { spot) }\end{array}$ \\
\hline $\mathrm{Cu}$ & $83.52 \pm 4.02$ & $79.42 \pm 3.13$ & $88.28 \pm 3.31$ & $91.03 \pm 3.31$ & $67.39 \pm 3.05$ & $89.91 \pm 3.86$ & $87.1 \pm 3.06$ \\
\hline $\mathrm{Pb}$ & $10.99 \pm 0.76$ & $2.55 \pm 0.22$ & $4.9 \pm 0.3$ & $3.1 \pm 0.21$ & $9.7 \pm 0.66$ & $0.09 \pm 0.04$ & $0.16 \pm 0.05$ \\
\hline Sn & $3.62 \pm 0.47$ & $17.21 \pm 1.12$ & $6.34 \pm 0.48$ & $5.25 \pm 0.41$ & $16.5 \pm 1.14$ & $9.7 \pm 0.77$ & $12.35 \pm 0.8$ \\
\hline Zn & $0.87 \pm 0.12$ & - & - & - & - & - & - \\
\hline $\mathrm{Fe}$ & $0.25 \pm 0.02$ & $0.5 \pm 0.03$ & $0.08 \pm 0.01$ & $0.17 \pm 0.01$ & $1.21 \pm 0.07$ & $0.05 \pm 0.01$ & $0.05 \pm 0.01$ \\
\hline $\mathrm{Ni}$ & $0.14 \pm 0.02$ & $0.11 \pm 0.01$ & $0.15 \pm 0.01$ & $0.21 \pm 0.01$ & $0.19 \pm 0.02$ & $0.11 \pm 0.01$ & $0.24 \pm 0.02$ \\
\hline As & $0.62 \pm 0.21$ & $0.21 \pm 0.09$ & $0.25 \pm 0.09$ & $0.23 \pm 0.08$ & $0.52 \pm 0.21$ & $0.08 \pm 0.02$ & $0.1 \pm 0.03$ \\
\hline $\mathrm{Ca}$ & - & - & - & - & $4.49 \pm 1.76$ & - & - \\
\hline
\end{tabular}


qualitative and quantitative elements' composition in certain spots chosen on the objects. After being polished and deprived of varnish, the two spots of interest on the metal were chosen for all objects. Furthermore, for the belt application XRF analysis was performed as well on a corrosion spot.

From the XRF results the necklace and belt application are copper-tin-lead alloy with elements variation: $\mathrm{Cu}$ from $79.42 \pm 3.13 \%$ (small bead of necklace) to $91.03 \pm 3.31 \%$ (belt application), $\mathrm{Pb}$ from $0.09 \pm 0.04 \%$ (button) to $10.99 \pm 0.76 \%$ (big bead of necklace), Sn from $3.62 \pm 0.47 \%$ (big bead of necklace) to $17.21 \pm 1.12 \%$ (small bead of necklace). The button results to be a copper-tin alloy where the elements vary as follows: $\mathrm{Cu}$ from $87.1 \pm 3.06 \%$ (edge spot) to $89.91 \pm 3.86 \%$ (top spot) and Sn from $9.7 \pm 0.77 \%$ (top spot) to $12.35 \pm 0.8 \%$ (edge spot). Elements such as Fe, $\mathrm{Zn}$ and $\mathrm{Ca}$ are present at a higher percentage on the corrosion spot compared to the metal ones on the belt application. Being chemical elements that serve as plans nutrition present in soil their percentage in the samples' alloy can be explained as contaminants. Fe, $\mathrm{Zn}$ and Ca reach a maximum value of $0.87 \pm 0.12 \%$ on metal spot ( $\mathrm{Zn}$ in big bead of necklace) and maximum $4.49 \pm 1.76 \%$ on corrosion spot (Ca in the belt application). The presents of As can be an evdence that the objects belong to the prehistoric times, because at the beginning of the objects' production this chemical element was unknown to be deadly. It has a maximum percentage of $0.62 \pm 0.21 \%$ on metal spot on the necklace big bead and $0.52 \pm 0.21 \%$ on corrosion spot of the belt application. Nickel is one of the four elements that characterise native copper (As, $\mathrm{Ni}, \mathrm{Pb}, \mathrm{Sb}$ ), but the usage of native copper in these alloys cannot be proved without further analysis. Ni values reach up to $0.24 \pm 0.02 \%$ on metal spot of the button (Tylecote, 1992).

Table 2 shows the results of the Vickers micro hardness test for each sample and the calculated mean values as well. From the Vickers test values the necklace (sample from small bead) and the button result with a higher micro hardness having a high content of tin. The belt application with a lower tin content (respectively 65 and $45 \%$ lower) but with a higher lead percentage (respectively 35 and $95 \%$ higher) compared to the necklace and button, has a mean micro hardness of 100.9 HV. Cast alloys have a lower microhardness than hot or cold worked ones and for the same tin content in cast bronzes (around 10\%) the increasing of lead percentage tends to decrease the microhardness (Scott, 1991).

Corrosion on ancient objects is formed during the time of manufacture (primary patina), of usage in the atmosphere (secondary patina) and during the time of burial in soil or water (tertiary or contamination patina). Even

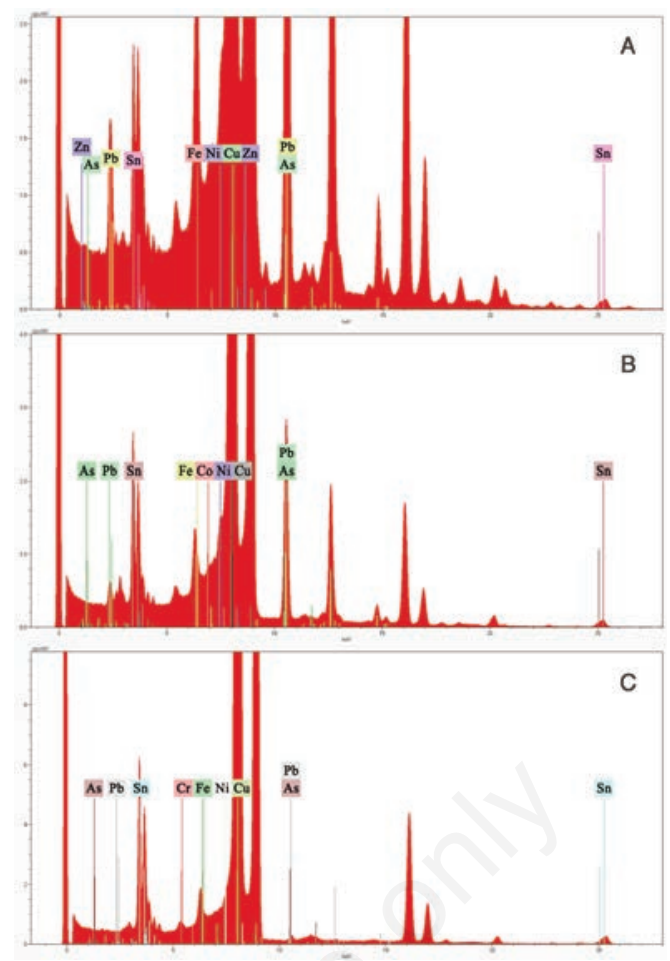

Figure 3. X ray fluorescence spectra of the first spot examined on each object: A) necklace, B) belt application, and C) button.

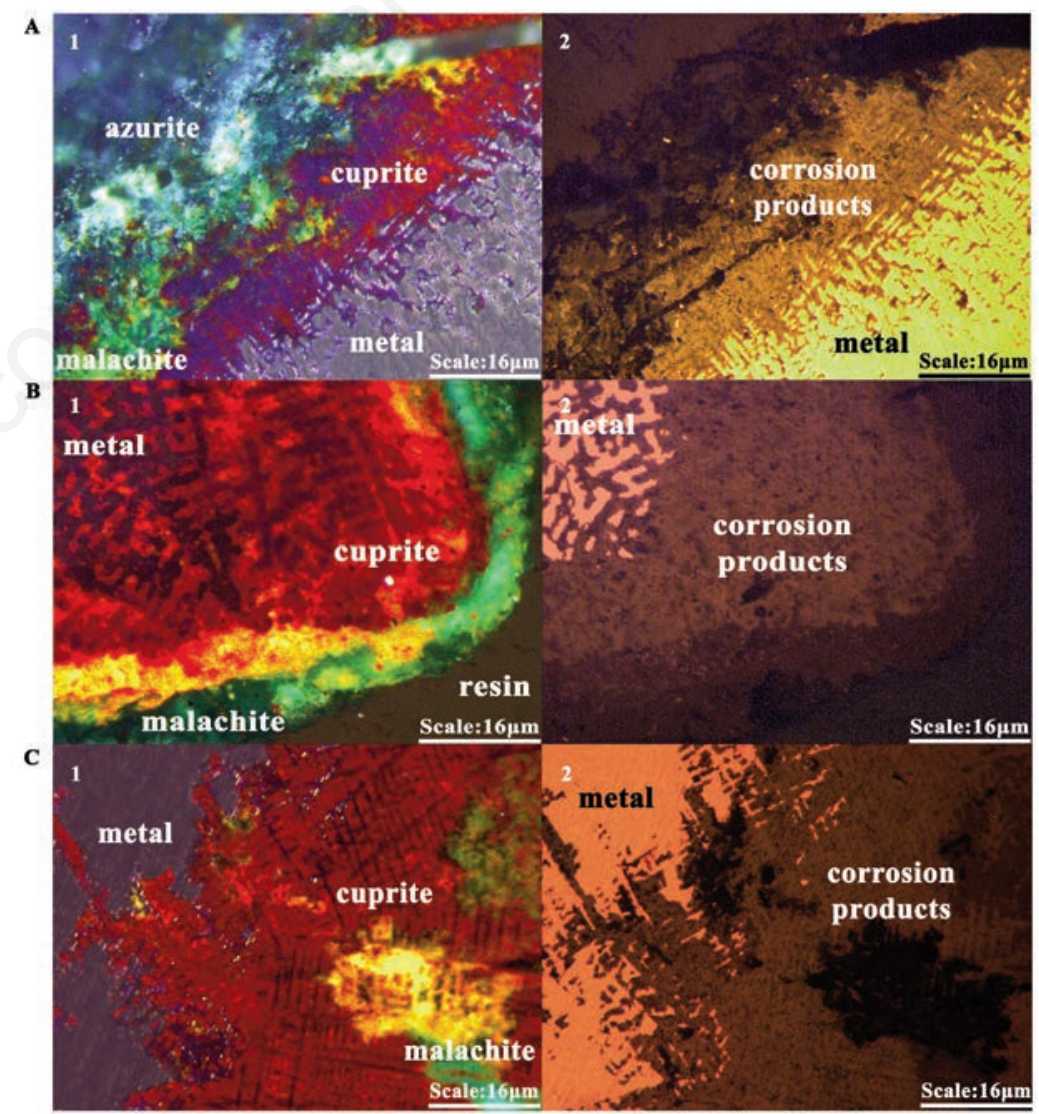

Figure 4. Photos with optical microscope for each sample: A) necklace, B) belt application, and C) button. Panels 1) show photos with crossed nicols polarised light of the corrosion products, while panels 2 ) with reflected light. The main corrosion products (first and second patina) were identified based on the literature (colours). 
objects composed by the exact same alloy can develop unique corrosion products depending on the soil composition. The primary patina that is formed around the alloy contains mainly cuprite/tenorite (red, orange, yellow): $4 \mathrm{Cu}+\mathrm{O}_{2} \rightarrow 2 \mathrm{Cu}_{2} \mathrm{O} / 2 \mathrm{Cu}+\mathrm{O}_{2} \rightarrow 2 \mathrm{CuO}$, which are products of copper interactions with atmospheric oxygen. The secondary patina is composed mostly of malachite/azurite (green, blue) and is created partly during the object usage (end of usage period) and partly during its burial: $2 \mathrm{CuO}+\mathrm{CO}_{2}+\mathrm{H}_{2} \mathrm{O} \rightarrow \mathrm{Cu}_{2}(\mathrm{OH})_{2}$ $\mathrm{CO}_{3} / \mathrm{CuO}+\mathrm{CO}_{2} \rightarrow \mathrm{Cu}\left(\mathrm{CO}_{3}\right)$. This layer lies above the primary patina and can also contain atacamite/paratacamite $\left[\mathrm{Cu}_{2}(\mathrm{OH})_{3} \mathrm{Cl}\right.$, bright to dark green] and brochantite/antlerite $\left[\mathrm{Cu}_{4} \mathrm{SO}_{4}\right.$ $(\mathrm{OH})_{6} / \mathrm{Cu}_{3}\left(\mathrm{SO}_{4}\right)(\mathrm{OH})_{4}$, green, black]. The last corrosion layer is formed during burial and consists of ankerite $\left[\mathrm{Ca}(\mathrm{Fe}, \mathrm{Mg}, \mathrm{Mn})\left(\mathrm{CO}_{3}\right)_{2}\right.$, brown, yellow, white]/gypsum $\left(\mathrm{CaSO}_{4} \bullet 2 \mathrm{H}_{2} \mathrm{O}\right.$, mainly colourless to white)/silicates (for example cassiterite $\mathrm{SnO}_{2}$ ) (Vink, 1986; Domenech-Carbo et al., 2008; Pracejus, 2008; Sandu et al., 2008, 2012, 2014; DomenechCarbo et al., 2011; Mircea et al., 2012). Figure 4 shows the corrosion products of all objects with crossed nicols (polariser and analyser) polarised light (left) with reflected light (right). It is clearly visible from the optical microscope photos with crossed nicols polarised and reflected light (Figure 4) that the corrosion is introduced far inside the alloy. This process takes hundreds of years and is impossible to be achieved artificially, meaning that these accessories are not fake replicas but authentic ones. Similar to etching, the corrosion process is a corrosive reaction and this is the reason why elements of the microstructure are visible in these photos (with polarised and reflected light) without using aqueous ferric chloride. In the necklace, belt application and button photos the dendrites along the corrosion products are visible. The corrosion products have high oxygen content and since this element cannot be detected from the $\mu$-XRF device, its percentage is automatically added from the analytical software to the other elements such as $\mathrm{Cu}, \mathrm{Sn}, \mathrm{Pb}$, etc.

After etching the samples with aqueous ferric chloride for several seconds (necklace 4 sec, belt application 6 and button $4 \mathrm{sec}$ ) the microstructure elements appear distinctly (Figure 5). Just as expected from the corrosion products photos the necklace, the belt application and the button have a dendritic microstructure which can be explained with a casting process in moulds. The dendrites are straight, which means that no cold working was performed after casting. Taking into account that the objects are ornamental accessories, this might have happened because the main purpose of production was to give a desirable shape to the alloy than to increase its hardness. Copper tin alloys are divided into

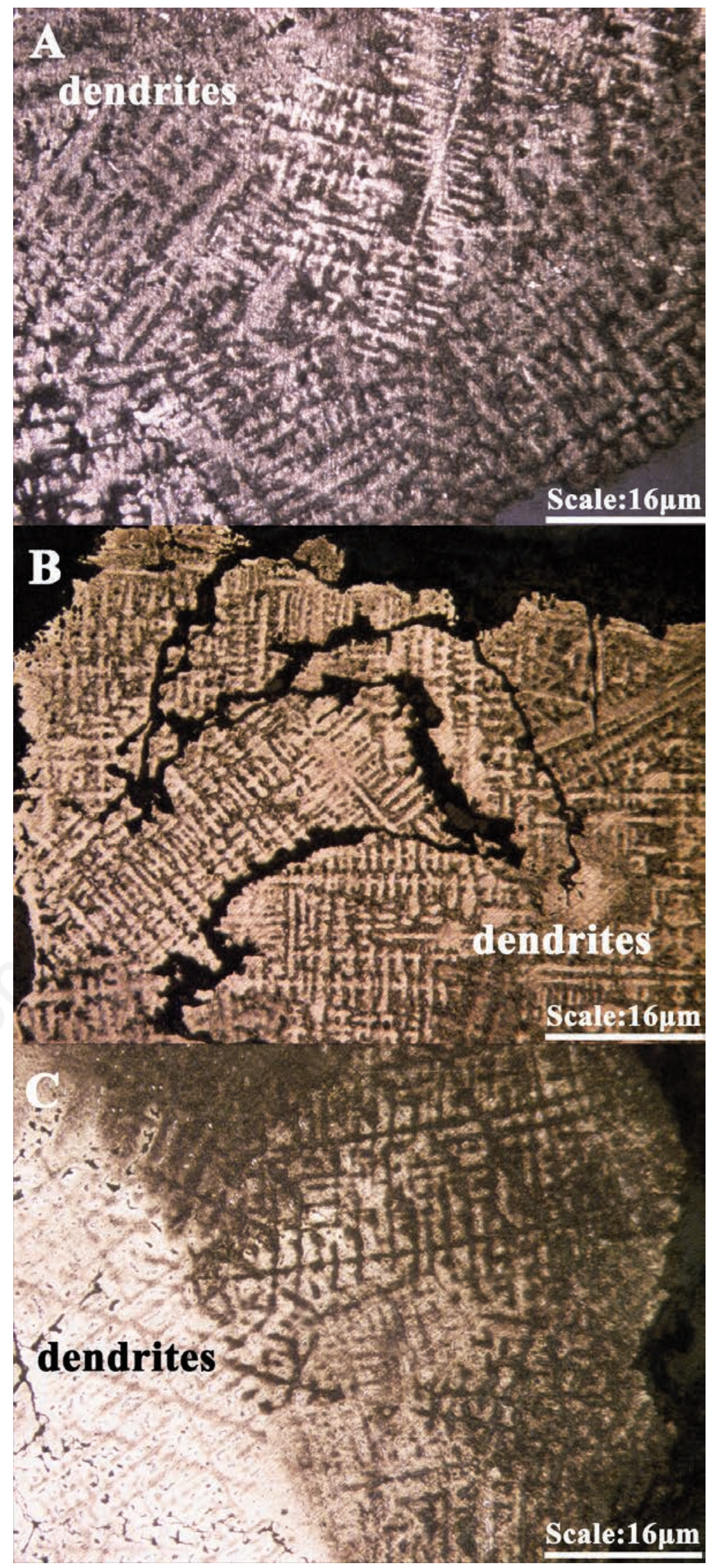

Figure 5. Photos with optical microscope with reflected light of the microstructure, after etching, for each sample: A) necklace (4 sec. etching), B) belt application ( 6 sec. etching) and $C$ ) button (4 sec. etching). 
Table 2. Measured and calculated mean values of the Vickers micro hardness test (for the rhombic trace diagonal $\Delta \mathrm{d}=0.5 \mu \mathrm{m}$ ).

\begin{tabular}{|c|c|c|c|c|c|c|c|c|c|}
\hline \multirow[t]{2}{*}{ Object } & \multirow[b]{2}{*}{ Test 1} & \multicolumn{7}{|c|}{ Vickers micro hardness } & \multirow[t]{2}{*}{$\overline{\mathrm{HV}}$} \\
\hline & & Test 2 & Test 3 & Test 4 & STest 5 & Test 6 & Test 7 & Test 8 & \\
\hline Necklace (small bead) & 122 & 130 & 130 & 127 & 123 & 133 & - & - & 127.5 \\
\hline Belt application & 105 & 94.9 & 104 & 101 & 95.8 & 96.7 & 104 & 106 & 100.9 \\
\hline Button & 142 & 121 & 119 & 117 & 121 & 140 & - & - & 126.6 \\
\hline
\end{tabular}

$\overline{\mathrm{HV}}$, hardness value.

low $(<17 \%)$ and high $(>17 \%)$ tin bronzes. Theoretically, $17 \%$ is the maximum tin content that can be completely dissolved in copper, practically this percentage can be around $14 \%$. The button is a low tin bronze where the centre of the dendrites is rich in copper because of the higher melting temperature. The dendrites growth is achieved by tin deposits and for tin bronzes with around $10 \% \mathrm{Sn}$, similar to the button sample, the dendrites are surrounded by + eutectoid. The low content of lead in the button makes the alloy hard to cast and the dendrites presence in the microstructure suggests that it might have been indeed casted. The very thin button build suggests that the mold was sophisticated in order to produce a low lead object. This could have been a rare occurrence taking into account the button dating. Adding lead in copper alloys, like in the necklace and belt application cases, lowers the alloy melting temperature and makes the casting process easier although this element is almost insoluble in copper. The low Sn percentage in the belt application suggests that this element could be absorbed completely in the dendrites growth. However, this depends significantly from the cooling rate, meaning that at a low cooling rate the equilibrium and tin absorption are more likely to occur. The small bead of the necklace cannot have a homogeneous microstructure phase because of the high tin content, which in theory is no longer completely soluble in copper. These alloys are usually unworkable and can only be casted (Scott, 1991).

\section{Conclusions}

From the XRF analysis that was performed on the samples, the button turns out to be a copper-tin alloy, while the necklace and the belt application are composed mainly of copper-tin-lead. Iron, zinc and calcium can be contaminations from the soil, being typical plant nutrition chemical elements. Arsenic and nick- el can indicate a prehistoric alloy. From the corrosion microscope photos it is clear that the ornamental accessories are authentic and not fake replicas. The dendritic microstructure indicates that the necklace, the belt application and the button might have been produced from a cast process in moulds with no further working. The necklace and the button, having a light tin content, result with the highest Vickers micro hardness values among the three samples. In fact, the belt application has a 20\% lower micro hardness value compared to the necklace and button, which could be explained with its higher lead content and lower tin percentage.

\section{References}

Boardman J, Edwards IES, Hammond NGL, Sollberger E, 1982. The Cambridge ancient history. The Prehistory of the Balkans, the Middle East and the Aegean world, tenth to eighth centuries BC. Cambridge University Press, Cambridge, UK.

Ceka N, 2000. Përpara se të shkruhej historia. In: N. Ceka (ed.) Ilirët. SHBLU Publ., Tirana, Albania, pp 36-7.

Domenech-Carbo A, Domenech-Carbo MT, Martinez-Lazaro I, 2008. Electrochemical identification of bronze corrosion products in archaeological artefacts. A case study. Microchim Acta 162:351-9.

Domenech-Carbo A, Domenech-Carbo MT, Trinidad P, Bouzas MC, 2011. Application of modified Tafel analysis to the identification of corrosion products on archaeological metals using voltammetry of microparticles. Electroanalysis 23:2803-12.

Jacques EE, 1995. The Albanians: an ethnic history from prehistoric times to the present. McFarland \& Company Inc., Jefferson, NC, USA.

Mircea 0, Sandu I, Vasilache V, Sandu AV, 2012. Study of the atypical formations in the corrosion bulks of an ancient bronze shield, by optical and electron microscopy. Microsc Res Techniq 75:1467-74.

MIT, 2003. The metallographic examination of archeological artifacts, laboratory manual. Massachusetts Institute of Technology ed., Cambridge, MA, USA.

Potts P, West M, 2008. Portable x-ray fluorescence spectrometry capabilities for in situ analysis. The Royal Society of Chemistry ed., London, UK.

Pracejus B, 2008. The ore minerals under the microscope, an optical guide. Elsevier, Amsterdam, The Netherlands.

Prendi F, 1958. Materiale të kulturës ilire të zbulueme në Shqipërinë e veriut. Bul Univ Shtet Tirane 2:110-32.

Prendi F, 1977-1978. Epoka e bronzit në Shqipëri. Iliria 7-8:5-58.

Prendi F, 2008. Studime arkeologjike. ARKKOS, Pristina, Kosovo.

Sandu I, Mircea 0, Sandu AV, Vasilache V, Sandu IG, 2014. Study of the Liesegang chemical effects in antique bronze artefacts during their stay within an archaeological site. Available from: http://www.revistadechimie.ro/article_eng. asp?ID=3980

Sandu I, Mircea 0, Vasilache V, Sandu I, 2012. Influence of archaeological environment factors in alteration processes of copper alloy artifacts. Microsc Res Techniq 75:1646-52.

Sandu I, Ursulescu N, Sandu IG, Bounegru I, Sandu ICA, Alexandru A, 2008. Pedological stratification effect of corrosion and contamination products on Bysantine bronze artefacts. Corros Eng Sci Techn 43:256-66.

Scott DA, 1991. Metallography and microstructure of ancient and historical metals. Tien Wah Press, Singapore.

Tylecote RF, 1992. A history of metallurgy. Antony Rowe Ltd., Croydon, UK.

Vink BW, 1986. Stability relations of malachite and azurite. Mineral Mag 50:41-7.

Wayne R, 2009. Light and video microscopy. Elsevier, Amsterdam, The Netherlands. 